\title{
Aggressive Resection in Patients with Advanced Pancreatic Neuroendocrine Tumors: Case Report and Review of the Literature
}

\author{
Jarboui $\mathrm{S}^{1}$, Hedfi $\mathrm{M}^{2}$, Jawher Baazaoui ${ }^{3}$, Aissaoui $\mathrm{L}^{4}$ and Ziedi Abelfettah ${ }^{5}$ \\ ${ }^{1}$ Department of General Surgery Sidi Bouzid Hospital, Tunisia \\ ${ }^{2,3}$ Department of General Surgery Regional Hospital of the Kef, Tunisia \\ ${ }^{4}$ Department of Gastroenterology Regional Hospital of the Kef, Tunisia \\ ${ }^{5}$ Department of Anatomopathology and cytology Regional Hospital of the Kef, Tunisia
}

Correspondence should be addressed to: Slim Jarboui ; drslimjarboui@yahoo.fr

Received date: 9 September 2013; Accepted date: 15 December 2013; Published date: 23 May 2014

Academic Editor: Félix Ignacio Téllez-Ávila

Copyright (C) 2014. Jarboui S, Hedfi M, Jawher Baazaoui, Aissaoui L and Ziedi Abelfettah. Distributed under Creative Commons CC-BY 3.0

\begin{abstract}
There is considerable controversy about the treatment of patients with malignant advanced pancreatic neuroendocrine tumors (PNETs). Aggressive surgery remains a potentially efficacious anti-tumor therapy but is rarely performed because of its possible morbidity and mortality. The purpose of this work is to describe a case of PNETs who underwent aggressive multivisceral pancreatic resection and the literature's review. Case report: A 52- year old man with no medical history, who presented for abdominal pain, recent constipation and intermittent rectal bleeding. Clinically, we found a tender mass of $10 \times 7 \mathrm{~cm}$ in the left upper quadrant. Colonoscopy revealed an irregular lesion of $2 \mathrm{~cm}$ in the splenic flexure with histological diagnosis at biopsies suggesting a pancreatic neoplastic origin. Computed tomography (CT) of the abdomen demonstrated a large mass in the left pancreas invading the spleen and its vessels, the adjacent left transverse colon with sign of segmental extrahepatic portal hypertension. There were no liver metastases or suspected adenopathies. He underwent laparotomy with extended resection of the left pancreas, the spleen and the left colon. Histological examination confirmed a well differentiated PNET with Ki67 < 2\%. The post operative course was uneventful. After 16 months of follow, the patient remains well. There is no sign of recurrence at CT. Conclusion: Many retrospective studies and the European neuroendocrine Tumors' (ENETs) guidelines claim that debulking and aggressive surgical resection in locally advanced PNETs should be considered in selected patients because it is technically feasible with encouraging disease-specific survival.
\end{abstract}

Keywords: Pancreas; Neuroendocrine Tumor; Debulking Surgery; Survive

Cite this Article as: Jarboui S, Hedfi M, Jawher Baazaoui, Aissaoui L and Ziedi Abelfettah (2014), "Aggressive Resection in Patients with Advanced Pancreatic Neuroendocrine Tumors: Case Report and Review of the Literature », International Journal of Case Reports in Medicine, Vol. 2014 (2014), Article ID 819525,

DOI: $10.5171 / 2014.819525$ 


\section{Introduction}

PNETs are relatively rare and represent a heterogeneous group of tumors with varying biology behaviour and prognosis. They can be classified as functional or non functional.

Advanced PNETs remain a difficult therapeutic challenge because of high malignant potential and resistance to conventional chemotherapy. Surgery with curative intent is the mainstay of treatment for these tumors, although, there have been recent developments with promising results by using novel agents like target therapy.

We highlight an example of large PNET requiring multivisceral resection and we do a literature's review to demonstrate that such complex operations can be achieved safely.

\section{Case report}

A 52- year old man presented with a three month history of progressive upper abdominal discomfort and constipation with intermittent rectal bleeding. There was no medical history. Clinically, he possessed a firm left upper quadrant with tender mass of 10x7 cm. Blood tests showed mildly anaemia: $\mathrm{Hb}: 10.2 \mathrm{~g} / \mathrm{dl}$. Because of recent change in his transit habits we performed a colonoscopy that revealed at the level of the splenic flexure an irregular formation without active bleeding. Endoscopic biopsies confirmed the neoplastic origin and its much suspected pancreatic origin, but they cannot distinguish between undifferentiated ductaltype adenocarcinoma and endocrine tumor. Chromogranine A (CgA) level was elevated at $2072 \mathrm{u} / \mathrm{l}$. CT of the abdomen, showed a large pancreatic mass $(10 \times 7 \times 5 \mathrm{~cm})$ invading the spleen and its vessels with segmental portal hypertension (PHT). The left transverse colon seemed in timely involved with the tumor (Fig.1).

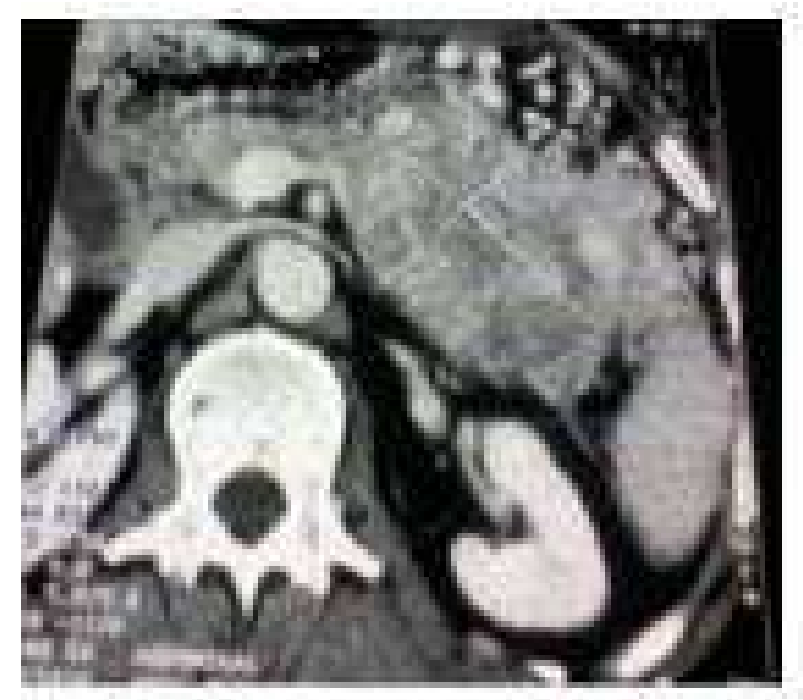

Figure 1-a: Computed tomography showing a huge tumor of the tail of the pancreas $(7 \times 10$ cm) 


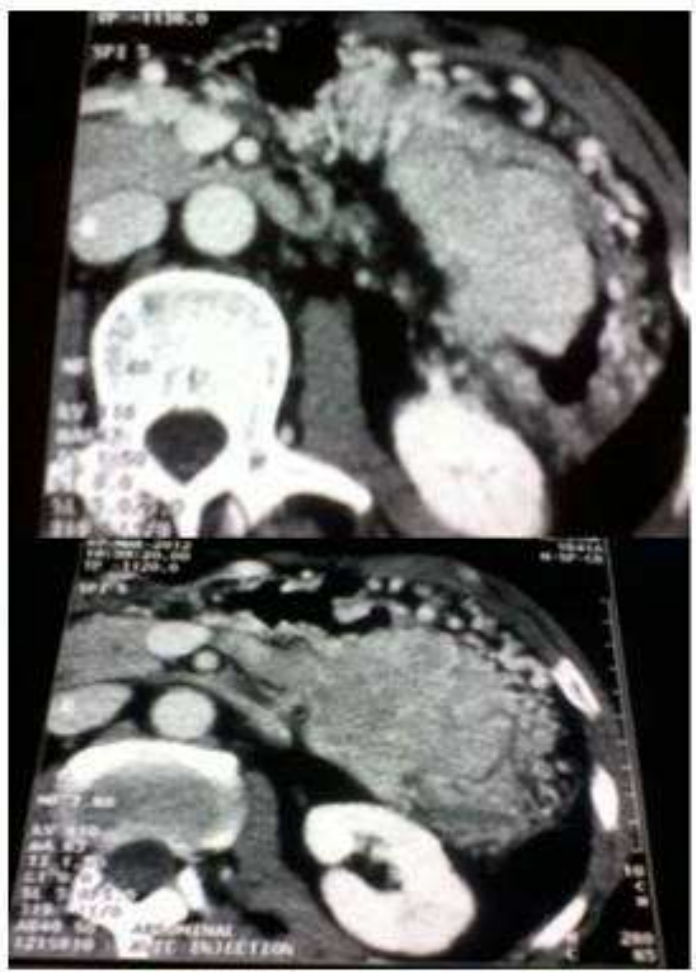

Figure 1-b: Invasion of the left colon with segmental portal vein hypertension

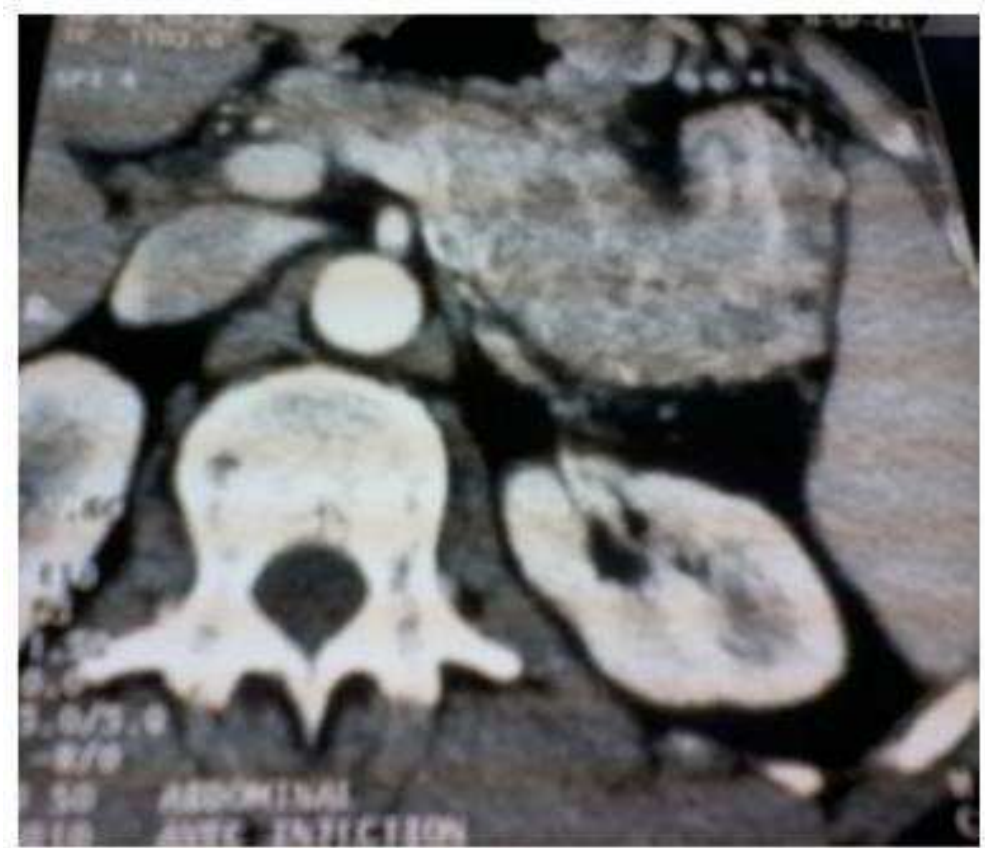

Figure 1-C: invasion of the spleen and splenic vessels.

Jarboui S, Hedfi M, Jawher Baazaoui, Aissaoui L and Ziedi Abelfettah (2014), International Journal of Case Reports in Medicine, DOI: 10.5171/2014.819525 
The stomach; the portal, superior mesenteric vein (SMV), the superior mesenteric artery (SMA) and the ceoliac trunk were not involved. The liver was free of disease and there was no suspected adenopathies particularly in the ceoliac and mesenteric space. At a multidisciplinary team meeting; consensus of opinion was that the patient should be offered resection. A midline laparotomy was performed. Exploration confirmed the left pancreatic mass invaded the spleen and its vessels, the adjacent transverse left colon, the great omentum with its gross veins (segmental PHT) that enrolled the tumoral mass. There was no metastasis in the liver at the visual and manual exploration. The SMV and SMA were identified in the infracolic compartment. Following mobilisation of the splenopancreatic mass with a dissection plane along the left Gerota's fascia, the left renal vein and left adrenal gland were not invaded. The left transverse colon was also mobilised and the short vessels were divided. We performed a bloc resection consisting of the left pancreas, the spleen, the great omentum and the left transverse colon. The neck of the pancreas was then transacted. The specimen was removed from the abdomen. (Fig.2).

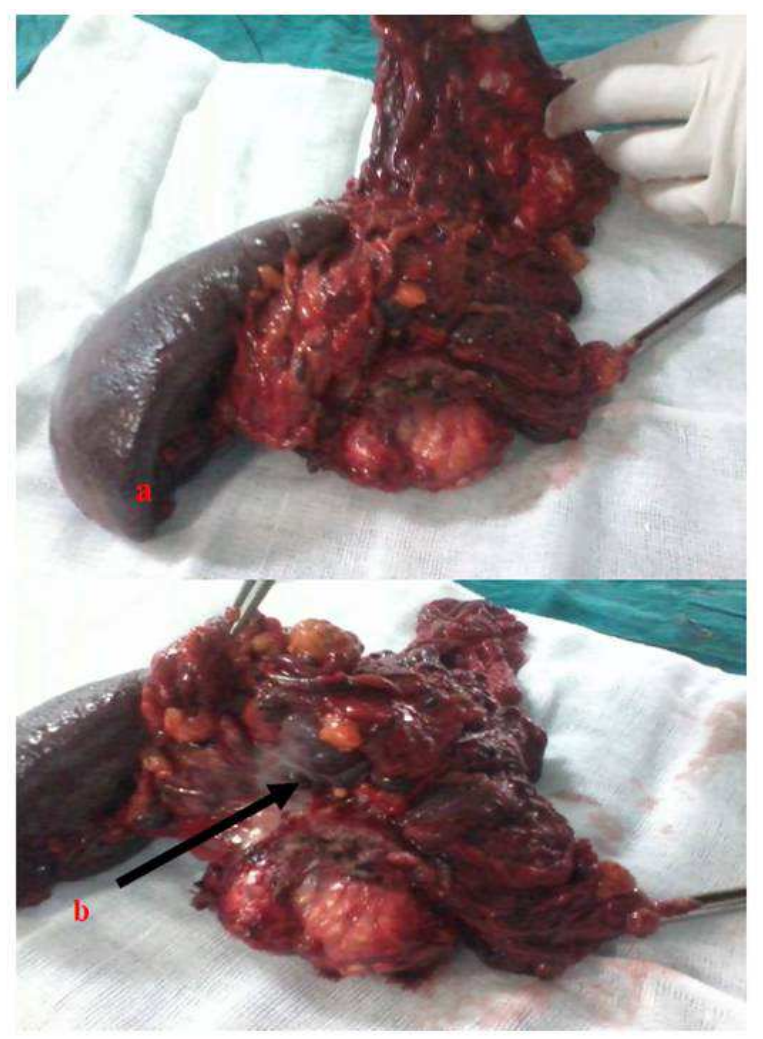

Figure 2 Operative specimen: a- En bloc resection comprising the spleen, the left pancreas and adjacent left transverse colon. $b$ - The pancreatic tumor invading the adjacent colon (arrow)

Reconstruction involved a side-side colocolic anastomosis. The pancreatic stump was closed with interrupted non resorbable suture (Prolen 4/0) with elective closure of 
the main pancreatic duct. The abdomen was drained and closed. Operative time was three hours with an estimated blood loss of $250 \mathrm{ml}$. Histopathological examination revealed a well differentiated PNET with $10 \mathrm{~cm}$ in diameter, with local invasion of the adjacent colon but all microscopic margins were clear (Fig.3). The mitotic rate was three mitosis per $10 \mathrm{HPL}$, and the Ki 67 proliferative index was $<2 \%$ (Fig.3).

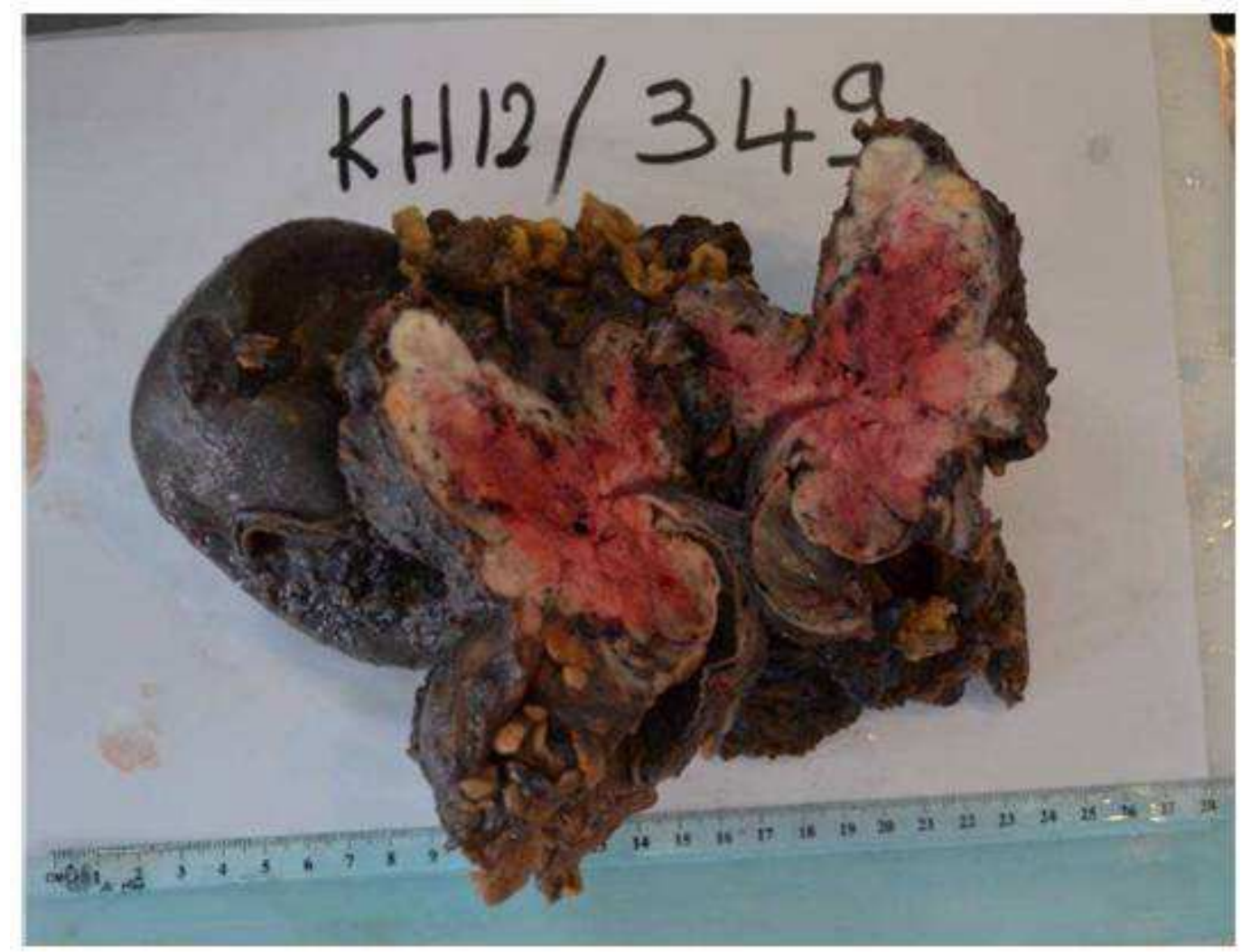

Figure 3: Macroscopic view of the specimen after formalin fixation

The post operative course was uneventful. He was discharged from hospital at $10^{\text {th }}$ day. The diagnosis of well differentiated pancreatic NET grade 1 is retained. There is no indication for adjuvant chemotherapy. Follow up showed a good functional recovery from surgery. The patient remains well 16 months following resection. CT scans at 3, 6 and 12 months showed no evidence of recurrence and the Chromogranine A level is decreased with sub normalization at 16 months of follow up.

\section{Discussion}

PNETs are rare neoplasms accounting for less than $3 \%$ of all pancreatic neoplasms [15]. They may be categorised as functional or non functional tumors based on the characteristic clinical syndrome they cause owing to specific hormone synthesis and secretion. Except for insulinoma; PNETs are malignant in more than $50-60 \%$ of cases. In various studies, 50 to $70 \%$ of patients with advanced disease have died within 5 years of tumor progression [1, 3, 4-6].

Our case report is particular because of its mode of revelation inherent to the involvement of adjacent left transverse colon causing transit change and rectal bleeding, the segmental PVH which had complicated 
the surgical procedure in this advanced stage tumor; and finally; the debulking and aggressive surgery that was attempted with the hope of achieving a long term disease free- survive.

The natural history of PNETs is difficult to predict despite advances in staging, grading and classification system. To enhance clinical decision making utility, these systems have recently been rationalised by ENETs in the form of clinical guidelines for diagnosis and management [7]. It is obvious that PNETs were more favourable than exocrine cancer in terms of outcomes and should therefore be addressed differently $[1,5,8,9]$. Surgery is the only potentially curative treatment for these tumors because chemotherapy and radiation therapy have not demonstrated any significant antitumor effects $[1,5,9]$. Furthermore, if all of the tumor can be removed with extensive surgery; the duration and quality of life may be greatly enhanced [9]. Multivisceral resection is defined as the resection of the pancreas and other organs not usually included in standard pancreatic operation [8]. The role of cytoreductive surgery remains controversial. Retrospective analyses have shown some survival benefit following surgery for locally advanced disease. In the retrospective study of Abou Hilal et al. [10], there has been a compiling 12 consecutive patients who underwent multivisceral en bloc resection for PNETs with a median of three additional organs resected. There were no post operative mortality and five patients experienced complications. They concluded that an aggressive approach is technically feasible and in selected patients can be achieved with low mortality and acceptable morbidity.

Resection of these advanced tumors is so desirable to ameliorate the mass effect; which can be fatal; and to reduce the incidence and severity of debilitating endocrine symptoms.

In the retrospective series published by Klein et al. [11], they analyse 41 patients who had consecutive resection for PNETs. Thirteen of whom underwent extended surgical resection in addition to pancreatic resection. There was no death in hospital stay. Patients who underwent extended resection had similar disease-specific survival to those who had pancreatic resection alone but with higher frequency complications. Furthermore, patients who had liver resection for metastases had similar disease specific survival to those without liver metastases. Other retrospective studies demonstrated the same results and concluded that conventional contraindications of surgical resection, such as SMV invasion, nodal or distant metastases, should be reconsidered in patients with advanced PNETs [12-17]. However, despite these conclusions, this evidence (as articulated in the ENETS guidelines) suffers from a heterogeneous patient/ tumor cohort and multimodality treatment strategies that make conclusions regarding aggressive surgery difficult to propose $[7,11,17]$.

With regard to liver metastases, a number of studies have shown that combined or staged resection and small volume metastatic liver disease improves survival outcomes [5,11,15-19]. ENETS guidelines [7] suggest that resection should only be reserved if at least $90 \%$ of the volume's tumor can be removed. In the study by TOUZIOS et al [18]; the median and 5- year survival rate were only 20 months and $25 \%$ for patients with their liver metastases treated in a non aggressive way, versus > 96 months and $72 \%$ for a group of patients who underwent hepatic resection and /or radiofrequency ablation of their liver disease. In the study by Fendrich et al [19], 27 patients with metastases from PNETs were treated surgically and a 5, 10 and actuarial 25-year survival rate of $81 \%, 72 \%$, and $36 \%$ respectively, was achieved. In the setting of PENTs with unresectable liver metastases, Capruso et al [20], in their systematic review, conclude that the resection of the primary is not recommended except for selected low risk patients with life-threatening symptoms due to complications of the primary lesions. 
Solorzano et al [21], reported survival data for 163 patients with PNETs. Among those with localized disease, an additional survival advantage was demonstrated for patients who underwent complete resection of the primary tumor, compared to those with unresectable tumors (7.2vs 5.2 years). The management of these inoperable patients may involve a spectrum of multimodality therapy. In highly selected cases, even liver transplantation may be considered [7, 10, 2126]. A number of biologically targeted agents targeting the VEGF and $m$ TOR signalling pathways have recently shown promise, with recent trials showing treatment with the VEGF tyrosine kinase inhibitor SUNITINIB or the mTOR inhibitor EVEROLIMUS improves progression free survival in patients with advanced PENTs [24-28]. The high rate of somatostatine receptor expression in PNETs also provides a rationale for peptide receptor radio nucleotide therapy in patients with inoperable or metastatic disease. The most frequently used radionucletides for targeted radiotherapy are Yttrium (90Y); and Lutetium (177LU) [28-31].

Future studies will likely build on these results; further improving therapeutic options for patients with advanced PNETs.

\section{Conclusion}

In conclusion, our case report and bibliographic findings suggest that surgical debulking in patients with advanced PNETs should be increasingly considered if all gross tumors can be safely removed. This extensive surgery can be performed with acceptable mortality rate. Although long-term cure can only be achieved in a proportion of patients with malignant PNETs, significant long-term palliation can be achieved. Its use coupled with adjuvant medical treatment (Somatostatin analogues, radiolabeled somatostatin analogues, or chemotherapy) should be systematically studied. This combination may result in enhanced survival rates.

\section{References}

1. Halfdanarson TR; Rabe K.G; Rubin J; Petersen G.M (2008). Pancreatic neuroendocrine tumors (PNETs): incidence, prognosis and recent trend toward improved survival. Ann of Oncology, 19:1727-1733.

2. Niederle M.B; Hack M; Kaserer K; Niederle B (2011). Gastroenteropancreatic neuroendocrine tumors: the current incidence and staging based on the WHO and European Neuroendocrine Tumor Society Classification: an anlysis based on prospectively collected parameters. Endocrine- related Cancer (2010), 17: 909 918.

3. Sandberg A (2011). A. Pancreatic endocrine tumors. North Am J Med Sci, 3: 164-166.

4. Mustafa E.S; Pechianu C; Iorgescu A; Hortopan M; Dima S.O; Tomulescu V et al (2012). Pathological characteristics and clinical specifications in gastropancreatic neuroendocrine tumors: A study of 68 cases. Rom J Morphol Embryol, 53: 351-355.

5. Philips S; Shah N; Vikram R; Verma S; Shanbhogue A.K.P; Prasad S.R (2012). Pancreatic endocrine neoplasm: a current update on genetics and imaging. The British Journal of Radiology, 85: 682-696.

6. Pape U.F; Jann H; Muller-Nordhom J; Bockelbrink A; Berndt U; Willich S.N; Koch M; Rocken C; Rindi G; Wiedenmann B (2008). Prognostic Relevance of a novel TNM Classification System for Upper Gastroenterpancreatic Neuroendocrine Tumors. Cancer, 113: 256-265.

7. Falconi M. Plakkinger; Kwekkeboom D et al (2006). Well-differentiated pancreatic non functioning tumors/ carcinoma. Neuroendocrinology, 84: 196-211.

8. Barreto SG; Shukla PJ; Shrikhande SV (2010). Tumors of the Pancreatic Body and Tail. World J Oncol, 1: 52-65.

9. Gundara J.S; Alvardo-Bachman R; Williams N; Gananadha S; Gill A; Hugh T.J; Samra JS(2011) . Multivisceral resection of 
pancreatic neuroendocrine tumours: a report of two cases. WJSO, 9: 93.

10.Abu Hilal M; Mc Phail Mark JW; Zeidan Bashar A; Jones Ceri E; Johnson Colin D; Pearce Neil W (2009). Aggressive Multivisceral Pancreatic resection for Locally Advanced Neuroendocrine Tumors. Is it worth it? JOP, 10: 276-279.

11.Kleim M; Schrem H; Vondran FW; Krech T; Klempnauer J; Bektas H. (2012) Extended surgery for advanced pancreatic endocrine tumours. Br J Surg, 99: 88-94.

12. Norton J.A; Kivlen M; Li M; Schneider D; Chuter T; Jensen RT (2003). Morbidity and Mortality of Aggressive Resection in Patients with Advanced Neuroendocrine Tumors. Arch Surg, 138: 859-866.

13. Schurr PG; Strate T; Rese K. Kaifi JT; Reichelt U; Petri S; Kleinhans H; Yekebas EF; Izbicki JR. Aggressive Surgery Long-term Survival Neuroendocrine Pancreatic Tumors. An Institutional Experience. Ann Surg, 245: 273-281.

14. Sasson AR; Hoffman JP; Ross EA; Kagan SA; Pingpank JF; Eisenberg BL. (2002) En Bloc resection for locally advanced cancer of the pancreas: is it worthwhile? J Gastrointest Surg, 6: 147-157.

15. Pingpank JF; Hoffman JP; Sigurdson ER; Ross E; Sasson AR; Eisenberg BL.(2002) Pancreatic resection for locally advanced primary and metastatic nonpancreatic neoplasm. Am Surg, 68: 337-340.

16. Fendrich V; Langer P; Celik I; Bartsch DK; Zielke A; Ramaswamy A; Rothmund M.(2006) An Aggressive Surgical Approach Leads to Long-term Survival in Patients with Pancreatic Endocrine Tumors. Ann Surg, 244: 845-853.

17.beke C.S; Prasad K.R; Toogood G.J; A Lodge J.P; Menon K.V.(2008) Results Following Surgical Resection for Malignant
Pancreatic Neuroendocrine Tumours. A Single Institutional Experience. JOP, 9: 19-25.

18. Touzios J.G; Kiely J.M; Pitt S.C; Rilling W.S; Quebbeman E.J; Wilson S.D; Pitt H.A. (2005) Neuroendocrine Hepatic Metastases. Does Aggressive Management Improve Survival? Ann Surg, 241: 776-785.

19. Fendrich V; Michi P; Habbe N; Bartsch DK. (2010). Liver-specific therapies for metastases of neuroendocrine pancreatic tumors. World J Hepatol; 2: 367-373.

20. Capurso G; Bettini R; Rinzivillo M; Bononsegna L; Dell Fave G; Falconi M.(2011) Role of Resection of the primary Pancreatic Neuroendocrine Tumor only in Patients With Unresectable Metastatic Liver Disease: A Systematic Review. Neuroendocrinology, 93: 223-229.

21. Solarzano CC (2001). Non functioning Iselt all Carcinoma of the Pancreas: Survival Results in a Contemporary Series of 163 Patients. Surgery, 130: 1078-1085.

22. Cerquiera M; Machado C. (2012) Surgical Treatment of Pancreatic Endocrine Tumors in Multiple Endocrine Neoplasia type 1. Clinics, 67: 145-148.

23. Yamazaki M; Suzuki S; Kosugi S; Okamoto T; Uchino S; Miya A; Imai T; Kaji H; Komoto I; Miura D; Yamada M; Uruno T; Horiuchi K; Sato A; Miyauchi A; Imamura M; Sakura I A; and MEN Consortium of Japan (2012). Delay in the diagnosis of multiple endocrine neoplasia type 1: typical symptoms are frequently overlooked. Advance Publication EJ 12-0071.

24. Tonelli F; Fratini G; Nesi G; Tommasi M.S; Batignani G; Falchetti A; Brandi M L. (2006) Pancreatectomy in Multiple Endocrine Neoplasia Type-1 Related Gstrinoma and Pancreatic Endocrine Neoplsias. Ann Surg, 244: 61-70.

25. Sarmiento JM; Heywood G; Rubin J; Llstrup DM; Nagorney DM; Que FG.(2003) 
Surgical treatment of neuroendocrine metastases to the liver: a plea for resection to increase survival. J Am Coll Surg, 197: 29-37.

26. Bruzoni M; Parikh P; Celis R; Are C; Ly QP; Meza JL; Sasson AR.(2009) Management of the primary tumor in patients with metastatic pancreatic Neuroendocrine tumor. A contemporary single-institution review. A, J Surg, 197: 376-81.

27. Bonavent $\mathrm{M}$; De Miquel MJ; GarciaCarbonero R. (2012) New Targeted Agent in Gastroenteropancreatic Neuroendocrine Tumors. Target Oncol, 7: 99-106.

28. Oberstein PE; Remotti H; Saif MW; Libutti SK.(2012) Pancreatic Neuroendocrine Tumors: Entering a New Era. Highlights from the "2012 ASCO Gastrointestinal Cancers Symposium" San Francisco, USA. January 1921, 2012. JOP, 13: 169-173.

29. Cen P; Amato RJ.(2012) Treatment of advanced pancreatic neuroendocrine tumors: potential role of Everolimus. Onco Targets and Therapy, 5: 217-224.

30. Saif MW; Ng J; Chang B; Russo S. (2012) Is There a Role of Radiotherapy in the Management of Pancreatic Neuroendocrine Tumors? Highlight from the "2012 ASCO Gastrointestinal Cancers Symposium" San Francisco, USA. January 19-21, 2012. JOP, 13: 174-176.

31. Dimou AT; Syrigos KN; Saif MW. (2010) Neuroendocrine Tumors of the Pancreas: What's new? Highlight from the "2010 ASCO Gastrointestinal Cancers Symposium" Orlondo, FL, USA. January 22-24, 2010. JOP, 11: $135-138$. 